\title{
Are emergency department clinical pathway interventions adequately described, and are they delivered as intended? A systematic review
}

International Journal of Care Coordination $0(0) \mathrm{I}-14$

(C) The Author(s) 2017

Reprints and permissions: sagepub.co.uk/journalsPermissions.nav DOI: 10.1 I77/2053434517732507 journals.sagepub.com/home/icp (S)AGE

\author{
Raffi Adjemian 1,2 ${ }^{1}$ Atbin Moradi Zirkohi ${ }^{2}$, Robin Coombs ${ }^{2}$, \\ Sharon Mickan ${ }^{1,3,4}$ and Christian Vaillancourt ${ }^{5,6}$
}

\begin{abstract}
Introduction: The accurate reproduction of clinical interventions and the evaluation of provider adherence in research publications improve the evaluation and implementation of research findings into clinical practice. We sought to examine the proportion of clinical pathway publications in an emergency department setting that adequately reported the following: (I) the exact reproduction of the clinical pathway that was implemented in the study, (2) the adherence to and correct execution of the clinical pathway intervention, and (3) the presence of a pre-implementation education phase.

Methods: We performed a descriptive systematic review of the literature from 2006 to 2015 using MEDLINE, EMBASE, CENTRAL, and CINAHL. All types of prospective trial designs were eligible. Validated clinical pathway criteria were used to identify relevant publications. Two reviewers independently collected data using a piloted data abstraction tool. Risk of bias was assessed using the Cochrane Effective Practice and Organization of Care Group Risk of Bias Tool and the Newcastle-Ottawa Scale.

Results: We identified 5947 publications, 44 of which met our inclusion criteria. The formal clinical pathway was fully reproduced in 27 (6I\%) publications, partially reproduced in 9 (21\%), and not reproduced in 8 (I8\%). Only I4 (32\%) studies reported whether at least one decision step was executed correctly. The presence of a pre-implementation education phase was reported in $33(75 \%)$ studies.

Conclusion: The underreporting of intervention elements may present a barrier to both the evaluation and accurate replication of clinical pathway interventions. These finding may be useful for the elaboration of complex intervention reporting guidelines, improved reporting in future clinical pathway publications, and improved knowledge translation and exchange of clinical pathway interventions.
\end{abstract}

\section{Keywords}

Clinical pathways, critical pathways, methodology, data reporting, emergency medicine, guideline adherence

\section{Introduction}

Clinical pathways (CPWs) are a type of complex intervention and a frequently used care strategy in Asia, Australia, Canada, Europe, the United Kingdom, and the United States. ${ }^{1-6}$ The modern emergency department $(\mathrm{ED})$ is a complex system consisting of multiple interdependent fragmented components, producing inconsistent levels of quality and safety, that require strategies to improve efficiency and patient flow within a coordinated and accountable system. ${ }^{7,8}$ CPWs may help actualize these strategies by: (1) increasing guideline adherence, (2) decreasing unwanted variation, (3) promoting patient safety, (4)
'Department of Primary Health Care, International Program in Evidence Based Health Care, University of Oxford, Oxford, UK

${ }^{2}$ Department of Family Medicine, McGill University, Quebec, Canada

${ }^{3}$ Nuffield Department of Primary Care Health Sciences, University of Oxford, Oxford, UK

${ }^{4}$ Gold Coast Health, Griffith University, Gold Coast, Australia

${ }^{5}$ Department of Emergency Medicine, University of Ottawa, Ottawa, ON, Canada

${ }^{6}$ Clinical Epidemiology Program, Ottawa Hospital Research Institute, University of Ottawa, Ottawa, ON, Canada

\section{Corresponding author:}

Raffi Adjemian, Department of Family Medicine, McGill University, I I 10 Pine Avenue West, Room 105, Montreal, Quebec H3A IA3, Canada.

Email: radjemian@hotmail.com 
improving patient satisfaction, and (5) optimizing resource allocation. ${ }^{4,9,10}$ Current CPWs have been effective in promoting best practices in a variety of ED presentations, such as asthma, ${ }^{11}$ myocardial infarction, ${ }^{12}$ and sepsis. ${ }^{13}$

Despite the potential of CPWs, there is general agreement that the description of complex interventions in clinical studies is inconsistent and incomplete. This problem is not specific to CPWs and exists across a variety of trial designs evaluating complex interventions. ${ }^{4,14-23}$ Additionally, although evaluating provider adherence to study interventions is a common theme in CPW research, ${ }^{9,24-28}$ relevant data are seldom collected in health care organizations using CPWs. ${ }^{27}$ From the standpoint of CPWs, these issues remain an important challenge for both the evaluation of the CPW literature and the widespread replication of effective CPW interventions. Until very recently, many of the reporting guidelines pertaining to complex interventions have concentrated on the assessment of the validity and presentation of results, rather than on the satisfactory description of the intervention being used. ${ }^{15}$ Amongst the newer reporting guidelines, ${ }^{29-36}$ three reporting characteristics seem to be particularly pertinent to CPWs: (1) the reproduction of the intervention that was used, (2) the reporting of adherence to interventions, and (3) the education of health care workers regarding the intervention.

The goal of this study is to focus on the reporting of the above three characteristics. We sought to determine the proportion of studies that: (1) provided a reproduction of the CPW document used by the clinicians who implemented the intervention; (2) measured the provider adherence to CPW components, including the appropriateness of execution of CPW steps which necessitated a decision to be made (decision steps); and (3) the proportion of publications that reported a pre-implementation teaching phase regarding the CPW intervention.

\section{Methods}

\section{Study design}

This study is a descriptive systematic review assessing three main reporting characteristics of $\mathrm{CPW}$ publications in the ED setting. CPW interventions were identified using criteria developed by Kinsman et al. ${ }^{22}$ [AQ1] We included the following trial designs: randomized controlled trials (RCTs), controlled clinical trials (CCTs), controlled before-after studies (CBA), interrupted time series (ITS), prospective cohort studies, and prospective simple before-after studies (SBA). We included both adult and pediatric patient groups and CPW interventions of any disease entity.
Publications, where the CPW was part of a multifaceted intervention, were included only if the CPW was the main focus of the study. We excluded the following: SBA studies where both the before arm and after arm were retrospective, conference abstracts, and doctoral theses. We also excluded studies where the continuum of CPW care involved the ED setting, but where the ED-related CPW care was not the focus of the publication.

\section{Search strategy}

We conducted a comprehensive search of MEDLINE, EMBASE, CENTRAL, and CINAHL from 2006 to 2015. We used a broad range of keywords in our search strategy, with free text in addition to the controlled vocabulary terms of individual databases. This is especially important for CPWs where the terminology is inconsistent. The search strategy was developed with the assistance of a medical librarian. Bibliographies of CPW systematic reviews were also searched for missed publications. We restricted the language of publication to either English or French. ${ }^{37} \mathrm{~A}$ complete description of the search strategy can be requested from the first author.

\section{Outcome measures}

Primary objetives. We examined three main outcome measures. The first was to ascertain the extent of the reproduction of the formal $\mathrm{CPW}$ utilized by the clinicians participating in the study. We classified the extent of CPW reproduction into three levels. A fully reproduced CPW is when the formal CPW utilized by the clinicians participating in the study was fully replicated in either the publication itself or in a supplementary document. A partially reproduced $\mathrm{CPW}$ is when indications in the text or graphical captions suggest that the described intervention was either an outline or a summary of the formal CPW, or when significant differences exist between what is described in the text and what is designated as the formal CPW. Non-reproduced implied that evidence of CPW replication was not found either in the original publication or in the supplementary material. Most CPWs are documented as a time-task chart in a graphical element of a publication. ${ }^{4}$ For this reason, we did not consider textual descriptions in lieu of the reproduction of a formal CPW. [AQ2]

The second outcome studied was the proportion of publications reporting provider adherence to at least one of two types of CPW steps: (1) non-decision steps, which represent interventions that all participants of a CPW receive and (2) decision steps, which represent a decision point where health care workers perform an action according to a pre-specified plan. 
Furthermore, since suboptimal adherence to CPW interventions generally results from the omission of an action or the inappropriate execution of a decision step, the proportion of publications reporting the appropriate execution of at least one decision step was evaluated. ${ }^{9}$ Adherence is known by many other terms such as variance analysis, variation, fidelity, protocol failure, protocol deviation, and implementation failure. However, for the purposes of simplicity, we have used the term adherence.

The third outcome was the measurement of the proportion of publications reporting any preimplementation education of clinical staff regarding the $\mathrm{CPW}$ intervention.

Secondary objectives. We examined a few secondary outcomes. First, since the fundamental objective of this systematic review is to gain insight into reporting characteristics of CPW interventions, we reviewed current reporting guidelines of complex interventions and summarized the guideline sections most relevant to our primary outcomes. Second, we examined the relationship between the length of CPWs, as determined by the number of decision steps, and CPW reproduction status. Third, we explored the possibility that certain publications did not fully reproduce their CPW intervention because the journal in question did not permit the inclusion of supplementary information. This was assessed by attempting to identify at least one other publication within the same journal/year that included supplementary information, either in the publication itself or in an accompanying document. Fourth, we examined the relationship between the appropriate execution of a CPW decision step and the reporting of a pre-intervention teaching phase.

\section{Study selection and data extraction}

CPW interventions were identified using criteria developed by Kinsman et al. ${ }^{22}$ We have recently validated these criteria and found them to be useful to reliably identify CPW publications for systematic review purposes in an ED setting. The methods of using these criteria to generate the publication set of the present systematic review are detailed in our recent publication. ${ }^{38}$

The criteria are as follows:

1. The intervention was a structured multidisciplinary plan of care;

2. The intervention was used to channel the translation of guidelines or evidence into local structures;

3. The intervention detailed the steps in a course of treatment or care in a plan, pathway, algorithm, guideline, protocol, or other inventory of actions;
4. The intervention had time frames of criteria-based progression (i.e., steps were taken if designated criteria were met);

5. The intervention aimed to standardize care for a specific clinical problem, procedure, or episode of care in a specific population.

The criteria are weighted; for an intervention to be considered a CPW, criterion 1 , and any three of the four remaining criteria have to be met.

Titles and abstracts of articles identified by the literature search were independently screened for eligibility by two sets of trained reviewers (RA/RC and RA/ AM), who subsequently applied CPW criteria to eligible full text publications. Data abstraction was done using a piloted standardized data extraction tool. Disagreements between reviewers were resolved by consensus and when necessary by a meeting of all investigators.

\section{Analytic strategy}

We used a descriptive approach to synthesize the results of the systematic review. Almost all of the data points were discrete quantities and are presented as raw numbers, proportions, or percentages. We assessed the extent of agreement between reviewers with Cohen's kappa coefficient with $95 \%$ confidence interval. Statistical analysis was performed using SPSS (version 20, IBM ${ }^{\mathrm{TM}}$ ).

\section{Assessment of study quality and bias}

We assessed RCTs, CCTs, ITS, and CBA studies with the Cochrane Effective Practice and Organization of Care Group Risk of Bias Tool. ${ }^{39}$ Since SBA studies are essentially a comparison of two cohort groups, we used the Newcastle-Ottawa Quality Assessment Scale. $^{40}$

\section{Results}

Figure 1 shows the number of studies included at each stage of the review. The search strategy identified 5947 publications. Of these, we retrieved 472 potentially relevant full text publications. Of the full text publications, 357 did not meet basic study inclusion criteria. The CPW criteria were applied to 115 studies with 44 publications being included ${ }^{9-11,39-79}$ and 71 excluded. The most common reasons for exclusion were that studies were either not prospective $(21.0 \%)$ or the intervention was not multidisciplinary $(15.4 \%)$.

Table 1 describes the general characteristics of included studies. The five most common clinical entities studied were sepsis $(30 \%)$, asthma $(16 \%)$, stroke/ 


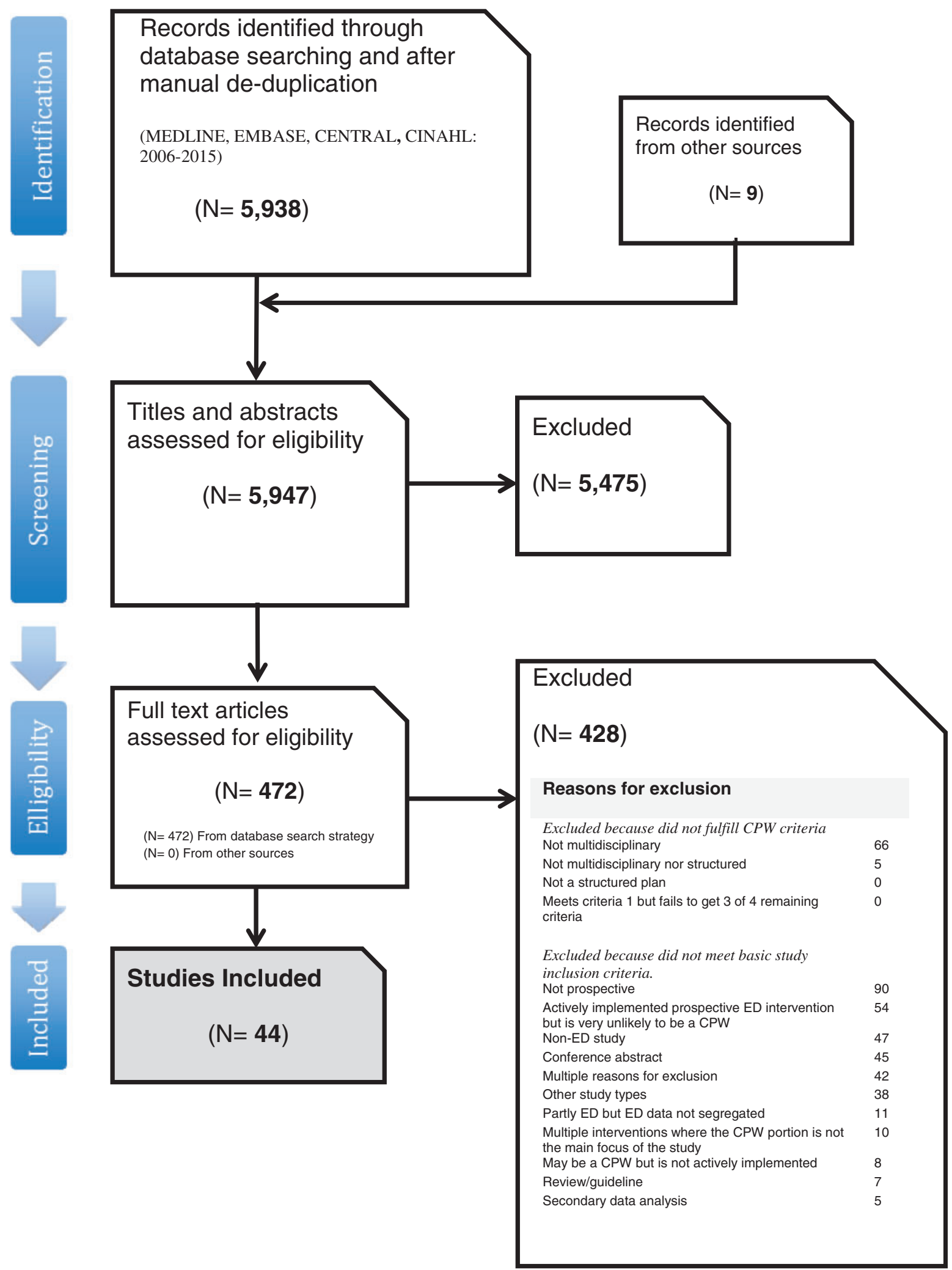

Figure I. Flow diagram of the review process.

CPW: clinical pathway; ED: emergency department. 
Table I. Characteristics of clinical pathway publications in the emergency department setting $(\mathrm{N}=44)$.

\begin{tabular}{|c|c|c|c|c|}
\hline Reference & Country & Study design & Study population & Clinical entity \\
\hline Andrews et al. ${ }^{55}$ & Zambia & RCT & Adult & Sepsis \\
\hline Bekmezian et al. ${ }^{56}$ & USA & SBA-rp & Both & Asthma \\
\hline Callegro et al. ${ }^{57}$ & Multinational & SBA-rp & Pediatric & Febrile seizures \\
\hline Calver et al. ${ }^{58}$ & Australia & SBA-rp & Adult & Acute behavioral disturbance \\
\hline Chen et al. ${ }^{59}$ & Taiwan & SBA-pP & Adult & Stroke \\
\hline Chern et al. $^{49}$ & USA & SBA-rp & Pediatric & CSF shunt malfunction \\
\hline Correia et al. ${ }^{60}$ & Brazil & SBA-PP & Adult & Myocardial infarction \\
\hline Crowe et al. ${ }^{61}$ & USA & SBA-rp & Adult & Sepsis \\
\hline Cruz et al. $^{62}$ & USA & SBA-rp & Pediatric & Sepsis \\
\hline Dalcin et al. ${ }^{63}$ & Brazil & SBA-pP & Both & Asthma \\
\hline Decostered et al. ${ }^{64}$ & Switzerland & SBA-pP & Adult & Acute pain \\
\hline Dexheimer et al. ${ }^{65}$ & USA & $\mathrm{RCT}$ & Pediatric & Asthma \\
\hline Ender et al. ${ }^{66}$ & USA & SBA-pP & Pediatric & Sickle cell disease \\
\hline Fong et al. ${ }^{67}$ & Australia & SBA-rp & Adult & Head injury \\
\hline Geurts et al. $^{52}$ & Netherlands & SBA-pP & Pediatric & Urinary tract infection \\
\hline Guse et al. ${ }^{51}$ & USA & SBA-rp & Both & Syncope \\
\hline Hoegerl et al. ${ }^{68}$ & USA & SBA-rp & Adult & Stoke \\
\hline Hyden et al. ${ }^{69}$ & USA & SBA-pP & Adult & Myocardial infarction \\
\hline Jones et al. ${ }^{70}$ & USA & SBA-pP & Adult & Sepsis \\
\hline Kim et al. ${ }^{71}$ & Korea & SBA-rp & Both & Pyelonephritis \\
\hline Lau et al. ${ }^{72}$ & Hong Kong & Prospective cohort & Adult & Stroke \\
\hline Li et al. $^{73}$ & Hong Kong & Prospective cohort & Adult & Urinary retention \\
\hline Lougheed et al." & Canada & CBA & Adult & Asthma \\
\hline Mackey et al. ${ }^{74}$ & Canada & SBA-pP & Both & Asthma \\
\hline MacRedmond et al. ${ }^{75}$ & Canada & SBA-rp & Adult & Sepsis \\
\hline McCarthy et al. ${ }^{50}$ & Ireland & SBA-rp & Adult & Chronic obstructive pulmonary disease \\
\hline Mohd et al. ${ }^{76}$ & Malaysia & Prospective cohort & Adult & Sepsis \\
\hline Munoz et al. ${ }^{77}$ & USA & SBA-rp & Adult & Hyperglycemia \\
\hline $\mathrm{Na}$ et al. ${ }^{78}$ & Multinational & Prospective cohort & Adult & Sepsis \\
\hline Nguyen et al. ${ }^{13}$ & USA & Prospective cohort & Adult & Sepsis \\
\hline Norton et al. ${ }^{79}$ & Canada & SBA-pP & Pediatric & Asthma \\
\hline Paul et al. ${ }^{53}$ & USA & SBA-rp & Pediatric & Sepsis \\
\hline Plambech et al. ${ }^{80}$ & Denmark & SBA-rp & Both & Sepsis \\
\hline Ratanalert et al. ${ }^{81}$ & Thailand & Prospective cohort & Both & Head injury \\
\hline Ross et al. $^{82}$ & USA & $\mathrm{RCT}$ & Adult & TIA \\
\hline Russel et al. ${ }^{83}$ & USA & SBA-rp & Pediatric & Appendicitis \\
\hline Sairanen et al. ${ }^{84}$ & Finland & Prospective cohort & Adult & Stoke \\
\hline Santillanes et al. ${ }^{85}$ & USA & Prospective cohort & Pediatric & Appendicitis \\
\hline Stead et al. ${ }^{86}$ & USA & Prospective cohort & Adult & TIA \\
\hline To et al. ${ }^{87}$ & Canada & SBA-rp & Pediatric & Asthma \\
\hline Tromp et al. ${ }^{88}$ & Netherlands & SBA-pP & Adult & Sepsis \\
\hline Wang et al. ${ }^{89}$ & China & SBA-pP & Adult & Sepsis \\
\hline Wilson et al. ${ }^{12}$ & Australia & SBA-pP & Adult & Myocardial infarction \\
\hline Yealy et al. ${ }^{54}$ & USA & RCT & Adult & Sepsis \\
\hline
\end{tabular}

aftrese studies used two terms eactr. [AQ7]

SBA (RP): Simple before-and-after (SBA) studies where the intervention is prospective and the control is retrospective; SBA (PP): SBA studies where both the intervention and the control phases are prospective; CBA: controlled before-and-after study; RCT: randomized control trial; CSF: cerebrospinal fluid; TIA: transient ischemic attacks.

transient ischemic attacks (14\%), myocardial infarction $(7 \%)$, and head injury $(5 \%)$. Most studies were performed in adults $(59 \%)$. The majority of included studies were SBA (30 of 44, 68\%). The before group of these studies were retrospective in 17 and prospective in 13 studies. A prospective cohort design was used in
$20 \%$ of studies. There were only four RCTs and one CBA study.

\section{CPW reproduction}

Figure 2 shows the proportion of included studies that reproduced the CPW either in the original publication 


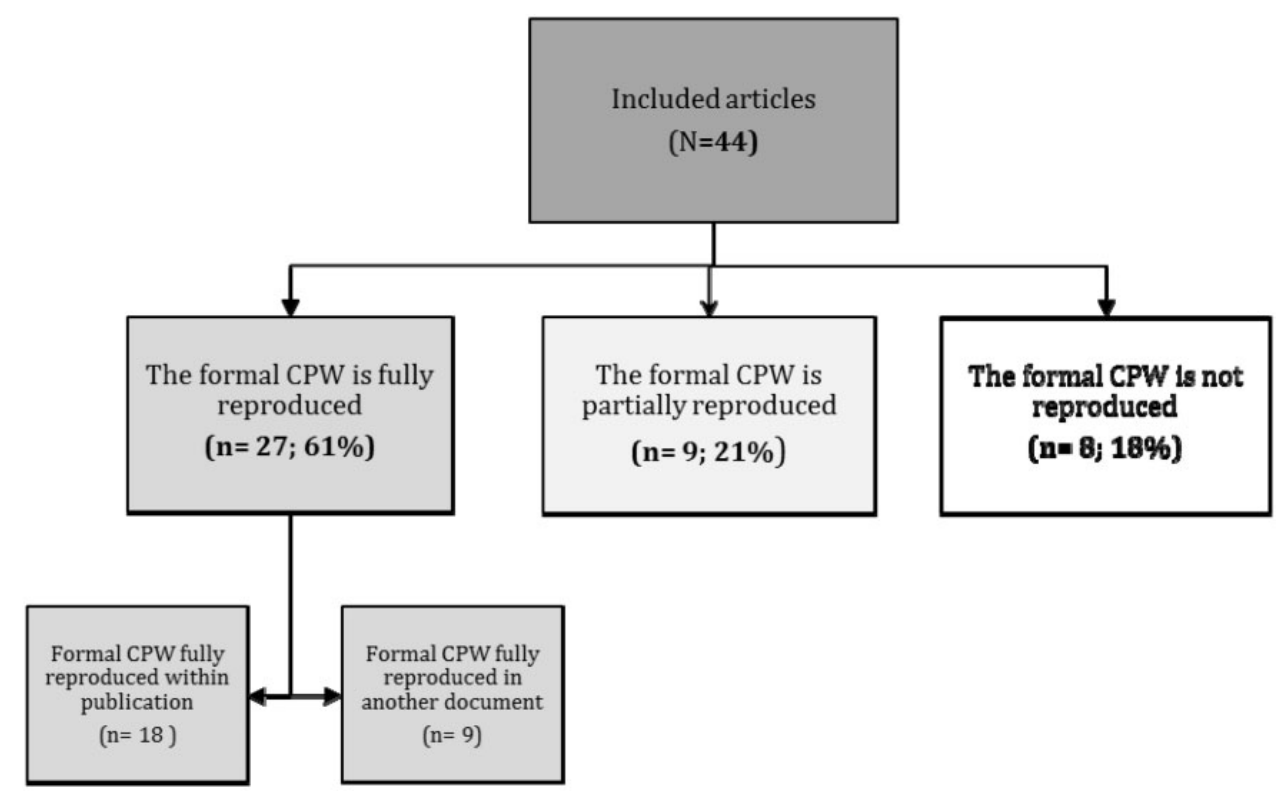

Figure 2. Reproduction of the formal CPW. CPW: clinical pathway.

or in an accessory document. Almost all publications stated that there was a formal CPW document; the identical written document utilized by the clinical staff performing the study intervention. Despite this, the formal CPW was fully reproduced in only 27 $(61 \%)$ of 44 publications. The majority of these were reproduced within the original publication, with nine being reproduced in an accessory document (four in a journal supplement, four in a second publication, and one in a website). Each of the 27 fully reproduced CPWs was presented either in a graphical form or as a time-task chart, usually as a table, a hierarchical figure, or a combination of the two. The CPW was partially reproduced in nine $(21 \%)$ studies. The CPW was not reproduced at all in eight $(18 \%)$ studies. The process of classifying interventions into the partially reproduced group was straightforward in eight of nine studies given that there were clear indications by the use of terms such as outline or summary. In one of nine studies, the reviewers judged the CPW reproduction to be incomplete based on a combination of a lack of textual description and graphical content. In one publication, the reader was referred to an accessory document, which may have contained the full formal CPW, but the website was expired, and we could not access the document.

Table 2 shows the relationship between the length of the $\mathrm{CPW}$, as measured by the number of decision steps, and the reproduction status of the intervention. The publications were divided into two groups. In the fully reproduced group, 8 (30\%) of 27 publications contained CPWs having $\geq 7$ decision steps. In partially or
Table 2. Length of clinical pathway (CPW) with respect to reproduction status.

\begin{tabular}{|c|c|c|c|}
\hline \multicolumn{2}{|c|}{$\begin{array}{l}\text { Publications with } \\
\text { fully reproduced } \\
\text { CPWs }(N=27)\end{array}$} & \multicolumn{2}{|c|}{$\begin{array}{l}\text { Publications with partially } \\
\text { or non-reproduced } \\
\text { CPWs }(\mathrm{N}=17)\end{array}$} \\
\hline $\begin{array}{l}\text { Decision } \\
\text { steps }\end{array}$ & $\begin{array}{l}\text { Number of } \\
\text { publications }\end{array}$ & $\begin{array}{l}\text { Decision } \\
\text { steps }\end{array}$ & $\begin{array}{l}\text { Number of } \\
\text { publications }\end{array}$ \\
\hline $1-3$ & 6 & $1-3$ & 7 \\
\hline $3-6$ & 13 & $3-6$ & 9 \\
\hline$\geq 7$ & 8 & $\geq 7$ & I \\
\hline Total & 27 & Total & 17 \\
\hline
\end{tabular}

A decision step implies that a participant received an element of care if they fulfilled a pre-specified condition. Decision steps are arbitrarily divided into three length categories.

non-reproduced publications only $1(6 \%)$ of 17 contained CPWs with $\geq 7$ steps.

Table 3 shows the capacity of journals to include supplemental information in publications not fully reproducing the intervention. In total, $13(76 \%)$ of 17 journals had the capacity to include supplemental information; 6 of 8 in the non-reproduced CPW group, and 7 of 9 in the partially reproduced CPW group.

\section{Adherence and execution of CPWs}

Table 4 shows the reporting of adherence to CPW components by the health care workers who executed the 
Table 3. Supplemental information capability of individual journals.

\begin{tabular}{ll}
\hline Reference & Supplemental information capability \\
\hline A non-reproduced clinical pathway publications $(\mathrm{N}=8)$ & \\
Andrews et al. & \\
Calver et al. & Supplement capability \\
Correia et al. & Open access web journal with no space constraints \\
Dalcin et al. ${ }^{63}$ & No supplement or within text appendix capability found \\
Kim et al. ${ }^{71}$ & Within publication appendix capability \\
Lau et al. ${ }^{72}$ & Supplement capability \\
Na et al. & No supplement or within text appendix capability found \\
Norton et al. & Supplement capability \\
B. Partially reproduced CPW publications $(\mathrm{N}=9)$ & Supplement capability \\
Chern et al. ${ }^{79}$ & \\
Cruz et al. ${ }^{62}$ & No supplement or within text appendix capability found \\
Hoegerl et al. ${ }^{68}$ & Supplement capability \\
Li et al. $^{73}$ & Supplement capability \\
Paul et al. ${ }^{53}$ & Within publication appendix capability \\
Ratanalert et al. ${ }^{81}$ & Supplement capability \\
Stead et al. ${ }^{86}$ & Supplement capability \\
Tromp et al. ${ }^{88}$ & No supplement or within text appendix capability found \\
Sairanen et al. ${ }^{84}$ & Supplement capability \\
\hline
\end{tabular}

Table 4. Reporting of provider adherence to clinical pathway (CPW) components.

\begin{tabular}{lll}
\hline & $\begin{array}{l}\text { Number of } \\
\text { publications }(\mathrm{N}=44)\end{array}$ & $\%$ Reported \\
\hline Non-decision step & 41 & 93 \\
Decision step & 41 & 93 \\
Decision step execution & 14 & 32 \\
\hline
\end{tabular}

Reporting of at least one step or appropriate execution of a decision step. A non-decision step is an element of care that all participants of the CPW should receive. A decision step implies that a participant received an element of care if they fulfilled a pre-specified condition.

intervention. Almost all publications reported provider adherence to at least one non-decision step and one decision step of the CPW. However, only $14(32 \%)$ of 44 measured the appropriateness of execution of at least one CPW component. Most of these publications explored the implications of suboptimal execution of CPW components in their discussion.

\section{Education regarding the CPW}

Three-fourths (33 of 44) of the publications discussed the presence of a pre-implementation education phase (figure not shown). In a secondary outcome, we found that 13 of these publications $(39 \%)$ also reported on provider adherence to the intervention. In contrast, only $1(9 \%)$ of 11 publications that failed to report about pre-implementation teaching reported about provider adherence.

\section{Assessment of risk of bias}

The vast majority of the included studies were of SBA or prospective cohort design. In general, there was a low to moderate risk of selection bias in both types of studies. The comparability of cohorts in SBA studies was inadequate with very few groups attempting to match groups and control confounding. The risk of bias was comparatively higher in the outcome assessment section in SBA studies with less than one-third reporting data from medical charts in a blinded fashion. The tables showing this data are presented elsewhere. ${ }^{38}$

\section{Reporting guidelines}

Table 5 shows reporting guidelines pertaining to complex interventions such as CPWs. We have divided the table into three columns, each reflecting the reporting elements of our three main outcome measures.

Table 5 (column A) shows the reporting items that pertain to the description of an intervention. Presently, the most explicit guidance regarding the description of an intervention is provided by the Template for Intervention Description and Replication (TIDieR). In particular, it explicitly recommends that authors provide information on where materials used in intervention delivery can be accessed, including online appendices and URLs. ${ }^{36}$ The Transparent Reporting of Evaluations with Nonrandomized Designs statement (TREND), and the Standards for QUality Improvement Reporting Excellence guideline (SQUIRE) provide fair guidance for the description 
Table 5. Characteristic of reporting guidelines applicable to complex interventions with regard to (A) intervention description, (B) provider adherence, and (C) pre-implementation education.

\begin{tabular}{|c|c|c|c|}
\hline Reporting guideline & $\begin{array}{l}\text { A } \\
\text { Intervention component } \\
\text { description/reproduction }\end{array}$ & $\begin{array}{l}\text { B } \\
\text { Adherence to intervention } \\
\text { components }\end{array}$ & $\begin{array}{l}\text { C } \\
\text { Pre-implementation } \\
\text { education }\end{array}$ \\
\hline $\begin{array}{l}\text { Revised CONSORT } \\
\text { statement } \\
\text { (Consolidated } \\
\text { Standards of Reporting } \\
\text { Trials) }^{29}\end{array}$ & $\begin{array}{l}\text { (4) Precise details of the inter- } \\
\text { ventions intended for each } \\
\text { group and how and when they } \\
\text { were actually administered }\end{array}$ & $\begin{array}{l}\text { (13) For each group, the num- } \\
\text { bers of participants who were } \\
\text { randomly assigned, received } \\
\text { intended treatment, and ana- } \\
\text { lyzed for the primary outcome }\end{array}$ & Not explicitly specified \\
\hline CONSORT $(\mathrm{RCT})^{30}$ & $\begin{array}{l}\text { (5) The interventions for each } \\
\text { group with sufficient details to } \\
\text { allow replication, including } \\
\text { how and when they were } \\
\text { actually administered }\end{array}$ & $\begin{array}{l}\text { (13a) For each group, the num- } \\
\text { bers of participants who were } \\
\text { randomly assigned, received } \\
\text { intended treatment, and were } \\
\text { analyzed for the primary } \\
\text { outcome }\end{array}$ & Not explicitly specified \\
\hline $\begin{array}{l}\text { CONSORT (Non-phar- } \\
\text { macologic trial } \\
\text { extension) }\end{array}$ & $\begin{array}{l}\text { (4A) Description of the different } \\
\text { components of the interven- } \\
\text { tions and, when applicable, } \\
\text { descriptions of the procedure } \\
\text { for tailoring the interventions } \\
\text { to individual participants }\end{array}$ & $\begin{array}{l}\text { (4c) Details of how adherence of } \\
\text { care providers with the pro- } \\
\text { tocol was assessed or } \\
\text { enhanced }\end{array}$ & $\begin{array}{l}\text { (4b) Details of how the } \\
\text { interventions were } \\
\text { standardized }\end{array}$ \\
\hline $\begin{array}{l}\text { CONSORT (Pragmatic } \\
\text { trial extension) }\end{array}$ & $\begin{array}{l}\text { (4) Describe the comparator in } \\
\text { similar detail to the } \\
\text { intervention }\end{array}$ & $\begin{array}{l}\text { (13) Report the numbers of } \\
\text { participants receiving intended } \\
\text { treatment, completing the } \\
\text { study protocol, etc. }\end{array}$ & $\begin{array}{l}\text { (4) Indicate if efforts were } \\
\text { made to standardize } \\
\text { the intervention or if } \\
\text { the intervention and its } \\
\text { delivery were allowed } \\
\text { to vary between par- } \\
\text { ticipants, practitioners, } \\
\text { or study sites }\end{array}$ \\
\hline $\begin{array}{l}\text { CReDECI (Criteria for } \\
\text { Reporting the } \\
\text { Development and } \\
\text { Evaluation of Complex } \\
\text { Interventions in } \\
\text { healthcare) } \\
\text { h3 }\end{array}$ & $\begin{array}{l}\text { (2) Description of all compo- } \\
\text { nents of the intervention } \\
\text { (II) Description of all materi- } \\
\text { als or tools used for the } \\
\text { implementation of the inter- } \\
\text { vention to allow a replication } \\
\text { of the study }\end{array}$ & $\begin{array}{l}\text { (13) Description of any deviation } \\
\text { from the study protocol } \\
\text { during the implementation } \\
\text { process }\end{array}$ & $\begin{array}{l}\text { (10) If the study was con- } \\
\text { ducted in different } \\
\text { clusters or centers: } \\
\text { description of a stan- } \\
\text { dardized implementa- } \\
\text { tion strategy } \\
\text { throughout the centers }\end{array}$ \\
\hline $\begin{array}{l}\text { SQUIRE (Standards for } \\
\text { QUality Improvement } \\
\text { Reporting Excellence) }\end{array}$ & $\begin{array}{l}\text { (9a) Describes the intervention } \\
\text { and its component parts in } \\
\text { sufficient detail that others } \\
\text { could reproduce it } \\
\text { (I 3ii) Explains the actual course } \\
\text { of the intervention (e.g., } \\
\text { sequence of steps, events or } \\
\text { phases; type and number of } \\
\text { participants at key points), } \\
\text { preferably using a time-line } \\
\text { diagram or flow chart }\end{array}$ & $\begin{array}{l}\text { ( } 3 \text { iii) Documents degree of } \\
\text { success in implementing inter- } \\
\text { vention components }\end{array}$ & $\begin{array}{l}\text { (9c) c) Outlines initial } \\
\text { plans for how the } \\
\text { intervention was to be } \\
\text { implemented-for } \\
\text { example, what was to } \\
\text { be done (initial steps; } \\
\text { functions to be accom- } \\
\text { plished by those steps; } \\
\text { how tests of change } \\
\text { would be used to } \\
\text { modify intervention) } \\
\text { and by whom (intended } \\
\text { roles, qualifications, and } \\
\text { training of staff) }\end{array}$ \\
\hline $\begin{array}{l}\text { TREND (Transparent } \\
\text { Reporting of } \\
\text { Evaluations with } \\
\text { Nonrandomized } \\
\text { Designs) }\end{array}$ & $\begin{array}{l}\text { (4) Details of the interventions } \\
\text { intended for each study con- } \\
\text { dition and how and when they } \\
\text { were actually administered, } \\
\text { specifically including: } \\
\text { Content: what was given? }\end{array}$ & $\begin{array}{l}\text { (12) Allocation and intervention } \\
\text { exposure: the number of par- } \\
\text { ticipants assigned to each } \\
\text { study condition and the } \\
\text { number of participants who } \\
\text { received each intervention }\end{array}$ & Not explicitly specified \\
\hline
\end{tabular}


Table 5. Continued

\begin{tabular}{|c|c|c|c|}
\hline Reporting guideline & $\begin{array}{l}\text { A } \\
\text { Intervention component } \\
\text { description/reproduction }\end{array}$ & $\begin{array}{l}\text { B } \\
\text { Adherence to intervention } \\
\text { components }\end{array}$ & $\begin{array}{l}\text { C } \\
\text { Pre-implementation } \\
\text { education }\end{array}$ \\
\hline $\begin{array}{l}\text { TIDieR (Template for } \\
\text { Intervention } \\
\text { Description and } \\
\text { Replication) } \\
\text { (6) }\end{array}$ & $\begin{array}{l}\text { Exposure quantity and dura- } \\
\text { tion: how many sessions or } \\
\text { episodes or events were } \\
\text { intended to be delivered? } \\
\text { How long were they intended } \\
\text { to last? } \\
\text { Time span: how long was it } \\
\text { intended to take to deliver the } \\
\text { intervention to each unit? } \\
\text { (3) What: Materials: Describe } \\
\text { any physical or informational } \\
\text { materials used in the inter- } \\
\text { vention, including those pro- } \\
\text { vided to participants or used } \\
\text { in intervention delivery or in } \\
\text { training of intervention pro- } \\
\text { viders. Provide information on } \\
\text { where the materials can be } \\
\text { accessed (such as online } \\
\text { appendix, URL) } \\
\text { (4) What: Procedures: Describe } \\
\text { each of the procedures, activ- } \\
\text { ities, and/or processes used in } \\
\text { the intervention, including any } \\
\text { enabling or support activities } \\
\text { (8) when and how much; } \\
\text { Describe the number of times } \\
\text { the intervention was delivered } \\
\text { and over what period of time } \\
\text { including the number of ses- } \\
\text { sions, their schedule, and their } \\
\text { duration, intensity, or dose }\end{array}$ & $\begin{array}{l}\text { (I I) How well: Planned: If inter- } \\
\text { vention adherence or fidelity } \\
\text { was assessed, describe how } \\
\text { and by whom, and if any } \\
\text { strategies were used to main- } \\
\text { tain or improve fidelity, } \\
\text { describe them } \\
\text { (I2) How well: Actual: If inter- } \\
\text { vention adherence or fidelity } \\
\text { was assessed, describe the } \\
\text { extent to which the interven- } \\
\text { tion was delivered as planned }\end{array}$ & $\begin{array}{l}\text { (3) What: Materials: } \\
\text { Describe any physical } \\
\text { or informational mate- } \\
\text { rials used in the inter- } \\
\text { vention, including those } \\
\text { provided to participants } \\
\text { or used in intervention } \\
\text { delivery or in training of } \\
\text { intervention providers. } \\
\text { Provide information on } \\
\text { where the materials can } \\
\text { be accessed (such as } \\
\text { online appendix, URL) } \\
\text { (4) What: Procedures: } \\
\text { Describe each of the } \\
\text { procedures, activities, } \\
\text { and/or processes used } \\
\text { in the intervention, } \\
\text { including any enabling } \\
\text { or support activities } \\
\text { (5) Who provided: For } \\
\text { each category of inter- } \\
\text { vention provider (such } \\
\text { as psychologist, nursing } \\
\text { assistant), describe } \\
\text { their expertise, back- } \\
\text { ground, and any specific } \\
\text { training given }\end{array}$ \\
\hline
\end{tabular}

Location of the item number within each reporting statement is given in parentheses.

of complex interventions in general and of the CPWs in particular. ${ }^{35,34}$ Furthermore, TREND adds elements of exposure quantity and a time dimension. SQUIRE further elaborates on the time dimension by suggesting that the reporting of a sequence of events may be illustrated with a graphical time line. However, neither specifically suggests that a duplicate of the intervention document, especially one that is complex in nature, be reproduced in the publication. In the case of RCTs, the Consolidated Standards of Reporting Trials statement (CONSORT) contains relatively little detail pertaining to complex intervention. ${ }^{29,30,33,41}$ Although the extensions to the CONSORT statement for pragmatic trials, ${ }^{32}$ and for non-pharmacologic interventions, ${ }^{31}$ provide better support for intervention development and implementation, relatively little guidance is offered for intervention description. ${ }^{42}$

There are numerous reasons for non-adherence to an intervention including those specific to health care providers, patients receiving the care, and the health care context. ${ }^{25}$

Table 5 (column B) shows that all the reporting guidelines include this element. However, only CONSORT and TIDieR specifically address provider adherence.

Table 5 (column C) shows that only about one-half of reporting guidelines (CONSORT, CreDIci (Criteria 
for Reporting the Development and Evaluation of Complex Interventions in healthcare), TREND, and TIDieR) comment on the importance of teaching health care providers about the intervention. TIDieR is the most explicit guideline for this element by unambiguously stating the need to report the "training of intervention providers." ${ }^{36}$

\section{Discussion}

This systematic review assessed three important reporting elements of CPWs in an ED setting. We found that approximately $40 \%$ of publications did not fully reproduce the CPW. This may result in the inadequate appraisal and evaluation of the study intervention, as well as imprecise replication in another environment. Furthermore, although almost all the included studies provided a measure of adherence to at least one nondecision step and one decision step, only a minority of the studies verified whether a decision step was executed correctly. Suboptimal adherence to the intervention may not only affect the magnitude of the study results but also its direction and ultimately the conclusions that are drawn regarding the study. We found that a high number of studies $(75 \%)$ reported the use of a preimplementation educational strategy. This may facilitate the adherence and proper execution of $\mathrm{CPW}$ components.

In complex interventions, it is often unclear which active ingredient $(s)$ is responsible for the effect outcome. $^{42-44,19}$ This suggests that from the perspective of implementation, the omission of even a single CPW component may result in unforeseen outcomes. Even with the best intentions, given the multiple steps involved in any pathway, an author may easily and unintentionally omit a detail from the intervention description. We found that only $61 \%$ of ED CPW publications fully reproduced the intervention. However, almost all of them disclosed the presence of a formal CPW document, implying that a written document was available to health care workers implementing the CPW. Our findings mirror those of a recent publication where important information about the intervention was missing in nearly $50 \%$ of the publications studied. ${ }^{15}$ Moreover, the rate in nonpharmacological studies, often more complex in nature attained $70 \%$.

In a secondary outcome, we found that studies that fully reproduced the intervention were more likely to contain CPWs with $\geq 7$ decision steps than those that did not. One possible reason for this may be that authors felt that longer CPWs necessitated fully reproducing the intervention to facilitate understanding by the reader. Another possible reason is that partially reproduced CPWs may have had non-reported components that could have falsely decreased the number of calculated decision steps.

It is generally thought that the majority of journals, at least in the last decade, have the ability to electronically store supplemental information. ${ }^{18}$ We found that most medical journals that contained publications which failed to fully reproduce the CPW intervention, either provided online supplement capability or had space reserved in the original publication for an appendix. This finding suggests that space restrictions were not the main reason why a significant number of authors chose not to fully reproduce the CPW intervention.

The availability of the complete and transparent document can improve the ability of clinicians both to replicate the intervention and to adapt it as necessary to conform to their clinical context. ${ }^{15,18,20,36,45}$ Although the recent TIDieR guideline of complex interventions ${ }^{36}$ offers the best guidance on this topic, we suggest that the next iteration takes it a step further and explicitly recommends the inclusion of a reproduction of the intervention (preferably the final version), instead of merely suggesting that a "description" or "details" be provided. We also suggest that the name of the formal CPW intervention be explicitly stated in both the text and figures. In the case of a partially reproduced $\mathrm{CPW}$, we suggest that this be clearly labeled as such to help the reader determine the extent of the information available. Furthermore, we suggest that journals keep supplementary documentation as an accessible and permanent record in the original journal archive. Although it is understandable that certain publications have supplements on independent websites, changes in URLs, a common enough occurrence, can affect access to these documents. For example, in one of the publications that fully reproduced the CPW in a website, the exact address given in the original publication did not result in document access. ${ }^{13}$ Instead, a shortened root of the URL was queried, and the document was found through the web menu of the site. Archiving a referenced web page of a publication can help preserve this information to perpetuity. ${ }^{46}$ Finally, we suggest that when a reference is made to a supplementary document, the page, figure, or table number should also be given to avoid errors in interpretation. For example, the web publication referred to above failed to do this for their 20-page document, where the relevant reproduced $\mathrm{CPW}$ was contained solely on a single web page.

The vast majority of our included studies were SBA studies, with an overall risk of bias that was low to moderate. However, it is important to note that despite having used an appropriate scale for SBA studies, neither this scale nor the scale we used for higher quality study designs such as cluster RCTs, CBA trials, 
specifically measure the adequacy of reporting about the intervention itself. ${ }^{39,40}$ Although the quality assessments of studies often focuses on their design and conduct. Studies with poor or inadequate reporting may represent an uncertain risk of bias. ${ }^{47,48}$ This is likely to especially relevant in studies of complex interventions such as CPWs.

The importance of evaluating adherence is a common theme in CPW research. ${ }^{9,24-28}$ However, data of provider adherence to interventions are seldom collected in health care organizations using CPWs. ${ }^{27}$ The TIDieR guideline provides excellent guidance for the reporting of intervention adherence, and we hope that future $\mathrm{CPW}$ publications will utilize it to improve reporting of this important component. ${ }^{36} \mathrm{We}$ found that only a minority of the studies verified whether a decision step was executed correctly. This finding is consistent with studies suggesting that inadequate execution is the result of most failures of adherence to intervention. ${ }^{9}$ Suboptimal reporting of provider adherence of key components of CPWs can affect the conclusions drawn about the results of a study. Furthermore, the incorrect execution of a decision step has another attribute that is important to consider; the directionality of its effect on an outcome is variable and therefore unpredictable. For example, in the included publications studying a cerebrospinal shunt malfunction pathway, the authors verified the accuracy of nurse triage into three "pathways" depending on the level of risk of a poor outcome (default, expedited, and emergency pathways) and found that "deviations from protocol" occurred in $19(18 \%)$ of 103 patients. ${ }^{49}$ These patients were all mistakenly assigned to the default group instead of the expedited group, leading to longer than expected "timeliness" of care. The authors believe that if the triage step were executed properly, it would improve timeliness of patient care. Importantly, if the same 19 patients were incorrectly placed in the expedited pathway, the effect on the outcome might have been in the opposite direction, that is, falsely shortening the timeliness of care.

We feel that ideally, the decision to measure the execution of a step will be greatly facilitated if it is decided a priori and built into the data gathering and analysis procedure of the publication. In fact, several of the publications in our study that reported on provider adherence to decisions steps included this as a study outcome. ${ }^{50-53}$ Notably, the highly cited ProCESS trial on sepsis had an innovative approach to measure provider execution of decisions steps. ${ }^{54}$ Not only did they include a complete reproduction of the CPW in a supplement, but they also provided a simplified version of the CPW that only displayed decision steps (which they called decision nodes). This allowed personnel in this multisite study (as well as readers wishing to replicate the study) to more easily and reliably measure the execution of decisions steps. In fact, this was the only publication found that provided execution data for every single decision step. We suggest that this methodology be used to facilitate and improve reporting of provider adherence in future studies of CPW and other complex interventions.

Three-fourths of the publications reported the presence of a pre-implementation education phase. This phase is important because it can indicate potential barriers that could have ultimately affected the study outcome. Additionally, it gives an indication of the time requirements and level of training needed for health care workers wishing to implement the CPW in another setting. In a secondary outcome, we found that publications reporting a teaching phase were more likely to also report on provider adherence to the intervention. This suggests that studies making an effort to improve adherence through pre-implementation education will also make an attempt to measure appropriate execution of the intervention. We feel that at present most reporting guidelines do not provide adequate guidance on the issue of teaching health care providers about the intervention. TIDieR is again the most explicit guideline for this element by unambiguously stating the need to report the "training of intervention providers." 36

There are a few limitations that need to be taken into account when interpreting the results. First, we did not contact authors to help get the reproduced intervention, similar to that done by Glasziou et al., ${ }^{15}$ [AQ3] because the point of the study was to assess the intrinsic quality of reporting in published interventions. Furthermore, the process of contacting authors for information comes with the risk of reporting bias.

Second, we hypothesized that journal publications not fully reproducing the CPW may have done so because of space considerations. This was assessed by attempting to identify at least one other publication within the same journal/year that included supplementary information in either the publication itself or in an accompanying document. This methodology may be inadequate if editorial decisions regarding the inclusion of supplementary information are done on a case-bycase example.

Third, it is possible that there are proprietary reasons why CPW interventions are not fully reproduced. Whether the ethical consideration of the potential waste of resources caused by the incomplete evaluation and implementation of these interventions should outweigh proprietary concerns is a matter of future debate.

Fourth, as with any systematic review, our study was susceptible to publication bias. In the case of our review, we did not examine the gray literature, particularly conference abstracts and dissertations, and we 
only included publications that were either in the English or French language, both of which may have contributed to publication bias.

In summary, CPWs seem to be a promising quality improvement intervention in the ED setting. However, complete reproduction of the formal intervention in research publications, as well as reporting on provider adherence, remain significant challenges. Importantly, suboptimal adherence to the study intervention may affect the outcome in an unpredictable way. Additional research regarding these elements may improve CPW evaluation and ultimately knowledge translation and implementation into clinical practice.

\section{Acknowledgments}

This publication was part of an MSc in Evidence-Based Health Care at the University of Oxford, Oxford, UK.

\section{Declaration of conflicting interests}

The author(s) declared no potential conflicts of interest with respect to the research, authorship, and/or publication of this article.

\section{Funding}

The author(s) received no financial support for the research, authorship, and/or publication of this article.

\section{References}

1. Campbell M, Fitzpatrick R, Haines A, et al. Framework for design and evaluation of complex interventions to improve health. BMJ 2000; 321: 694-696.

2. Craig P, Dieppe P, Macintyre S, et al. Developing and evaluating complex interventions: the new Medical Research Council guidance. BMJ 2008; 337.

3. Pearson SD. Et tu, critical pathways? Am J Med 1999; 107: 397-398.

4. Vanhaecht K. The impact of clinical pathways on the organisation of care processes. $\mathrm{PhD}$ Thesis, Katholieke Universiteit Leuven, Belgium, 2007.

5. Zander K, Etheredge ML, Bower K. Nursing case management: blueprints for transformation. Boston, MA: New England Medical Center Hospitals, 1987.

6. Vanhaecht K, Panella M, Zelm R, et al. An overview on the history and concept of care pathways as complex interventions. Int J Care Pathw 2010; 14: 117-123.

7. Institute of Medicine. Hospital-based emergency care: at the breaking point - institute of medicine. 2006. [AQ4]

8. Institute of Medicine. Emergency medical services: at the crossroads. 2007. [AQ5]

9. Every NR, Hochman J, Becker R, et al. Critical pathways: a review. Circulation 2000; 101: 461-465.

10. Mould G, Bowers $\mathbf{J}$ and Ghattas M. The evolution of the pathway and its role in improving patient care. Qual Saf Health Care 2010; 19: 1-6.

11. Lougheed MD, Olajos-Clow J, Szpiro K, et al. Multicentre evaluation of an emergency department asthma care pathway for adults. Can J Emerg Med 2009; 11: 214-229.

12. Willson AB, Mountain D, Jeffers JM, et al. Door-to-balloon times are reduced in ST-elevation myocardial infarction by emergency physician activation of the cardiac catheterisation laboratory and immediate patient transfer. Med J Aust 2010; 193: 207-212.

13. Nguyen HB, Corbett SW, Steele R, et al. Implementation of a bundle of quality indicators for the early management of severe sepsis and septic shock is associated with decreased mortality. Crit Care Med 2007; 35: 1105-1112.

14. Armstrong R, Waters E, Moore L, et al. Improving the reporting of public health intervention research: advancing TREND and CONSORT. J Public Health (Oxf) 2008; 30: 103-109.

15. Glasziou P, Meats E, Heneghan C, et al. What is missing from descriptions of treatment in trials and reviews? BMJ 2008; 336: 1472-1474.

16. Glenton C, Underland V, Kho M, et al. Summaries of findings, descriptions of interventions, and information about adverse effects would make reviews more informative. J Clin Epidemiol 2006; 59: 770-778.

17. Lamb SE, Becker C, Gillespie LD, et al. Reporting of complex interventions in clinical trials: development of a taxonomy to classify and describe fall-prevention interventions. Trials 2011; 12: 125.

18. Michie S, Fixsen D, Grimshaw JM, et al. Specifying and reporting complex behaviour change interventions: the need for a scientific method. Implement Sci 2009; 4: 40.

19. Oakley A, Strange V, Bonell C, et al. Process evaluation in randomised controlled trials of complex interventions. BMJ 2006; 332: 413-416.

20. Riley BL, MacDonald J, Mansi O, et al. Is reporting on interventions a weak link in understanding how and why they work? A preliminary exploration using community heart health exemplars. Implement Sci 2008; 3: 27.

21. Rychetnik L, Frommer M, Hawe P, et al. Criteria for evaluating evidence on public health interventions. J Epidemiol Commun Health 2002; 56: 119-127.

22. Kinsman L, Rotter T, James E, et al. What is a clinical pathway? Development of a definition to inform the debate. BMC Med 2010; 8: 31.

23. Thomson R. Evidence based implementation of complex interventions. BMJ 2009; 339: b3124.

24. Brown SW and Nameth LS. Questions to ask: implementing a system for clinical pathway variance analysis. Outcomes Manag Nurs Pract 1998; 2: 57-62; quiz 62-63.

25. Campbell H, Hotchkiss R, Bradshaw N, et al. Integrated care pathways. BMJ 1998; 316: 133-137.

26. De Bleser L, Depreitere R, De Waele K, et al. Defining pathways. J Nurs Manag 2006; 14: 553-563.

27. Hyett KL, Podosky M, Santamaria N, et al. Valuing variance: the importance of variance analysis in clinical pathways utilisation. Aust Health Rev 2007; 31: 565-570.

28. Vanhaecht K, De Witte K, Depreitere R, et al. Clinical pathway audit tools: a systematic review. J Nurs Manag 2006; 14: 529-537.

29. Altman DG, Schulz KF, Moher D, et al. The revised CONSORT statement for reporting randomized 
trials: explanation and elaboration. Ann Intern Med 2001; 134: 663-694.

30. Schulz KF, Altman DG and Moher D. CONSORT 2010 statement: updated guidelines for reporting parallel group randomised trials. BMJ 2010; 340: c332.

31. Boutron I, Moher D, Altman DG, et al. Extending the CONSORT statement to randomized trials of nonpharmacologic treatment: explanation and elaboration. Ann Intern Med 2008; 148: 295-309.

32. Zwarenstein M, Treweek S, Gagnier JJ, et al. Improving the reporting of pragmatic trials: an extension of the CONSORT statement. BMJ 2008; 337: a2390.

33. Mohler R, Bartoszek G, Kopke S, et al. Proposed criteria for reporting the development and evaluation of complex interventions in healthcare (CReDECI): guideline development. Int J Nurs Stud 2012; 49: 40-46.

34. Ogrinc G, Mooney SE, Estrada C, et al. The SQUIRE (Standards for QUality Improvement Reporting Excellence) guidelines for quality improvement reporting: explanation and elaboration. Qual Saf Health Care 2008; 17 Suppl 1: i13-i32.

35. Des Jarlais DC, Lyles C and Crepaz N. Improving the reporting quality of nonrandomized evaluations of behavioral and public health interventions: the TREND statement. Am J Public Health 2004; 94: 361-366.

36. Hoffmann TC, Glasziou PP, Boutron I, et al. Better reporting of interventions: template for intervention description and replication (TIDieR) checklist and guide. BMJ 2014; 348: g1687.

37. Morrison A, Polisena J, Husereau D, et al. The effect of English-language restriction on systematic review-based meta-analyses: a systematic review of empirical studies. Int J Technol Assess Health Care 2012; 28: 138-144.

38. Adjemian R, Zirkohi AM, Coombs R, et al. Validation of descriptive clinical pathway criteria in the systematic identification of publications in emergency medicine. Int $J$ Care Coord 2017; 20: 45-56.

39. Cochrane Effective Practice and Organization of Care Group (EPOC). Suggested risk of bias criteria for EPOC reviews, http://epoc.cochrane.org/sites/epoc.cochrane.org/ files/uploads/Suggested risk of bias criteria for EPOC reviews.pdf (2009, accessed 6 September 2017). [AQ6]

40. Wells GA, Shea B, O'Connell D, et al. The NewcastleOttawa Scale (NOS) for assessing the quality of nonrandomised studies in meta-analyses, http://www.ohri.ca/pro grams/clinical_epidemiology/oxford.asp (2008, accessed 6 September 2017).

41. Mayo-Wilson E. Reporting implementation in randomized trials: proposed additions to the consolidated standards of reporting trials statement. Am J Public Health 2007; 97: 630-633.

42. Shepperd S, Lewin S, Straus S, et al. Can we systematically review studies that evaluate complex interventions? PLoS Med 2009; 6.

43. Campbell NC, Murray E, Darbyshire J, et al. Designing and evaluating complex interventions to improve health care. BMJ 2007; 334: 455-459.

44. Shojania KG and Grimshaw JM. Evidence-based quality improvement: the state of the science. Health Aff (Millwood) 2005; 24: 138-150.
45. Grimshaw JM and Eccles MP. Is evidence-based implementation of evidence-based care possible? Med J Aust 2004; 180: S50-S51.

46. Thorp AW and Schriger DL. Citations to Web pages in scientific articles: the permanence of archived references. Ann Emerg Med 2011; 57: 165-168.

47. Higgins JPT and Green S (eds). Cochrane handbook for systematic reviews of interventions. Version 5.1.0, www. cochrane-handbook.org/ (2009, accessed 6 September 2017).

48. Viswanathan M, Ansari MT, Berkman ND, et al. Assessing the risk of bias of individual studies in systematic reviews of health care interventions. Agency for Healthcare Research and Quality Methods Guide for Comparative Effectiveness Reviews AHRQ Publication No 12-EHC047-EF, www.effectivehealthcare.ahrq.gov/, (2012, accessed 6 September 2017).

49. Chern JJ, Macias CG, Jea A, et al. Effectiveness of a clinical pathway for patients with cerebrospinal fluid shunt malfunction. J Neurosurg Pediatr 2010; 6: 318-324.

50. McCarthy C, Brennan JR, Brown L, et al. Use of a care bundle in the emergency department for acute exacerbations of chronic obstructive pulmonary disease: a feasibility study. Int J Chron Obstruct Pulmon Dis 2013; 8: 605-611.

51. Guse SE, Neuman MI, O'Brien M, et al. Implementing a guideline to improve management of syncope in the emergency department. Pediatrics 2014; 134: e1413-e1421.

52. Geurts DH, Vos W, Moll HA, et al. Impact analysis of an evidence-based guideline on diagnosis of urinary tract infection in infants and young children with unexplained fever. Eur J Pediatr 2014; 173: 463-468.

53. Paul R, Melendez E, Stack A, et al. Improving adherence to PALS septic shock guidelines. Pediatrics 2014; 133 : e1358-e1366.

54. Yealy DM, Kellum JA ,Huang DT, et al. A randomized trial of protocol-based care for early septic shock. $N$ Engl J Med 2014; 370: 1683-1693.

55. Andrews B, Muchemwa L, Kelly P, et al. Simplified severe sepsis protocol: a randomized controlled trial of modified early goal-directed therapy in Zambia. Crit Care Med 2014; 42: 2315-2324.

56. Bekmezian A, Fee C and Weber E. Clinical pathway improves pediatrics asthma management in the emergency department and reduces admissions. J Asthma 2015; 52: 806-814.

57. Callegaro S, Titomanlio L, Donega S, et al. Implementation of a febrile seizure guideline in two pediatric emergency departments. Pediatr Neurol 2009; 40: 78-83.

58. Calver LA, Downes MA, Page CB, et al. The impact of a standardised intramuscular sedation protocol for acute behavioural disturbance in the emergency department. BMC Emerg Med 2010; 10: 14.

59. Chen CH, Tang SC, Tsai LK, et al. Stroke code improves intravenous thrombolysis administration in acute ischemic stroke. PLoS One 2014; 9: e104862.

60. Correia LCB, Brito M, Kalil F, et al. Effectiveness of a myocardial infarction protocol in reducing door-toballon time. Arq Bras Cardiol 2013; 101: 26-34. 
61. Crowe CA, Mistry CD, Rzechula K, et al. Evaluation of a modified early goal-directed therapy protocol. Am J Emerg Med 2010; 28: 689-693.

62. Cruz AT, Perry AM, Williams EA, et al. Implementation of goal-directed therapy for children with suspected sepsis in the emergency department. Pediatrics 2011; 127: e758-e766.

63. Dalcin PdTR, da Rocha PM, Franciscatto E, et al. Effect of clinical pathways on the management of acute asthma in the emergency department: five years of evaluation. J Asthma 2007; 44: 273-279.

64. Decosterd I, Hugli O, Tamches E, et al. Oligoanalgesia in the emergency department: short-term beneficial effects of an education program on acute pain. Ann Emerg Med 2007; 50: 462-471.

65. Dexheimer JW, Abramo TJ, Arnold DH, et al. Implementation and evaluation of an integrated computerized asthma management system in a pediatric emergency department: a randomized clinical trial. Int $\mathrm{J}$ Med Inform 2014; 83: 805-813.

66. Ender KL, Krajewski JA, Babineau J, et al. Use of a clinical pathway to improve the acute management of vaso-occlusive crisis pain in pediatric sickle cell disease. Pediatr Blood Cancer 2014; 61: 693-696.

67. Fong C, Chong W, Villaneuva E, et al. Implementation of a guideline for computed tomography head imaging in head injury: a prospective study. Emerg Med Australas 2008; 20: 410-419.

68. Hoegerl C, Goldstein FJ and Sartorius J. Implementation of a stroke alert protocol in the emergency department: a pilot study. J Am Osteopath Assoc 2011; 111: 21-27.

69. Hyden R and Fields W. Improving the acute myocardial infarction rapid rule out process. J Nurs Care Qual 2010; 25: 313-319.

70. Jones AE, Focht A, Horton JM, et al. Prospective external validation of the clinical effectiveness of an emergency department-based early goal-directed therapy protocol for severe sepsis and septic shock. Chest 2007; 132: 425-432.

71. Kim K, Lee CC, Joong ER, et al. The effects of an institutional care map on the admission rates and medical costs in women with acute pyelonephritis. Acad Emerg Med 2008; 15: 319-323.

72. Lau AY, Soo YO, Graham CA, et al. An expedited stroke triage pathway: the key to shortening the doorto-needle time in delivery of thrombolysis. Hong Kong Med J 2010; 16: 455-462.

73. Li YK, Leung CS, Hui TL, et al. Acute urinary retention: how useful is an ambulatory care protocol? Hong Kong $J$ Emerg Med 2009; 16: 134-140.

74. Mackey D, Myles M, Spooner $\mathrm{CH}$, et al. Changing the process of care and practice in acute asthma in the emergency department: experience with an asthma care map in a regional hospital. Can J Emerg Med 2007; 9: 353-365.

75. MacRedmond R, Hollohan K, Stenstrom R, et al. Introduction of a comprehensive management protocol for severe sepsis is associated with sustained improvements in timeliness of care and survival. Qual Safety Health Care 2010; 19: e46.

76. Salleh FM, Fathil SM, Ahmad Z, et al. Early goaldirected therapy in the management of severe sepsis/ septic shock in an academic Emergency Department in Malaysia. Crit Care Shock 2010; 13: 91-97.

77. Munoz C, Villanueva G, Fogg L, et al. Impact of a subcutaneous insulin protocol in the emergency department: rush emergency department hyperglycemia intervention (REDHI). J Emerg Med 2011: 493-498.

78. Na S, Kuan WS, Mahadevan M, et al. Implementation of early goal-directed therapy and the surviving sepsis campaign resuscitation bundle in Asia. Int $J$ Qual Health Care 2012; 24: 452-462.

79. Norton SP, Pusic MV, Taha F, et al. Effect of a clinical pathway on the hospitalisation rates of children with asthma: a prospective study. Arch Dis Child 2007; 92: 60-66.

80. Plambech MZ, Lurie AI and Ipsen HL. Initial, successful implementation of sepsis guidelines in an emergency department. Dan Med J 2012; 59: A4545.

81. Ratanalert S, Kornsilp T, Chintragoolpradub N, et al. The impacts and outcomes of implementing head injury guidelines: clinical experience in Thailand. Emerg Med J 2007; 24: 25-30.

82. Ross MA, Compton S, Medado P, et al. An emergency department diagnostic protocol for patients with transient ischemic attack: a randomized controlled trial. Ann Emerg Med 2007; 50: 109-119.

83. Russell WS, Schuh AM, Hill JG, et al. Clinical practice guidelines for pediatric appendicitis evaluation can decrease computed tomography utilization while maintaining diagnostic accuracy. Pediatr Emerg Care 2013; 29: 568-573.

84. Sairanen T, Soinila S, Nikkanen M, et al. Two years of Finnish Telestroke: thrombolysis at spokes equal to that at the hub. Neurology 2011; 76: 1145-1152.

85. Santillanes G, Simms S, Gausche-Hill $M$, et al. Prospective evaluation of a clinical practice guideline for diagnosis of appendicitis in children. Acad Emerg Med 2012; 19: 886-893.

86. Stead LG, Bellolio MF, Suravaram S, et al. Evaluation of transient ischemic attack in an emergency department observation unit. Neurocrit Care 2009; 10: 204-208.

87. To T, Wang C, Dell SD, et al. Can an evidence-based guideline reminder card improve asthma management in the emergency department? Respir Med 2010; 104: 1263-1270.

88. Tromp M, Hulscher M, Bleeker-Rovers CP, et al. The role of nurses in the recognition and treatment of patients with sepsis in the emergency department: a prospective before-and-after intervention study. Int J Nurs Stud 2010; 47: 1464-1473.

89. Wang Z, Xiong Y, Schorr C, et al. Impact of sepsis bundle strategy on outcomes of patients suffering from severe sepsis and septic shock in China. J Emerg Med 2013; 44: 735-741. 